\title{
Synthesis, Crystal Structure and Thermal Properties of Lead(II) Complex with Bathophenanthroline and Benzoyltrifluoroacetonate Ligands
}

\author{
Saeideh Hosseini, ${ }^{1}$ Farzin Marandi, ${ }^{2}$ Ertan Şahin, ${ }^{3}$ and Seyid Javad Musevi ${ }^{4}$ \\ ${ }^{1}$ Department of Chemistry, Islamic Azad University, Karaj Branch, Karaj, Iran \\ ${ }^{2}$ Department of Chemistry, Payame Noor University, Tehran 19395-3697, Iran \\ ${ }^{3}$ Department of Chemistry, Atatürk University, 25240 Erzurum, Turkey \\ ${ }^{4}$ Department of Chemistry, Shahid Beheshti Technical Faculty, Technical and Vocational University, Urmia, Iran
}

Correspondence should be addressed to Farzin Marandi; f.marandi@gmail.com

Received 13 April 2012; Accepted 15 May 2012

Academic Editor: Jorge Barros-Velazquez

Copyright (C) 2013 Saeideh Hosseini et al. This is an open access article distributed under the Creative Commons Attribution License, which permits unrestricted use, distribution, and reproduction in any medium, provided the original work is properly cited.

A new $\mathrm{Pb}$ (II) complex, $\left[\mathrm{Pb}(\mathrm{bp})_{2}(\mathrm{btfa})_{2}\right] \mathbf{1}$, has been synthesized with bathophenanthroline (bp) and benzoyltrifluoroacetone (Hbtfa) and characterized by elemental analysis IR and ${ }^{1} \mathrm{H}$ NMR spectroscopy as well as by thermal properties and X-ray crystallography. The coordination number of the $\mathrm{Pb}(\mathrm{II})$ ions in 1 is eight, with the $\mathrm{PbN}_{4} \mathrm{O}_{4}$ coordination polyhedron containing a stereochemically "inactive" electron lone pair with holodirected coordination spheres. In solid state, there are $\pi \cdots \pi, \mathrm{C}-\mathrm{H} \cdots \mathrm{F}$, $\mathrm{C}-\mathrm{H} \cdots \mathrm{O}$, and $\mathrm{F} \cdots \mathrm{F}$ interactions between adjacent units to generate 3D supramolecular structure.

\section{Introduction}

The $\mathrm{Pb}^{2+}$ cation has a $[\mathrm{Xe}] 4 f^{14} 5 d^{10} 6 s^{2}$ electronic configuration and exhibits an especially versatile character with respect to the HSAB theory [1] for which it appears as a borderline acid, able to bind to wide families of ligands [2] within very flexible coordination modes $[3,4]$. The coordination chemistry of $\mathrm{Pb}(\mathrm{II})$ is mainly determined by two factors: (i) its large size (ionic radius $1.32 \AA$ [5], covalent radius $1.54 \AA$ [5] and van der Waals radius $2.00 \AA[6]$ ), which permits coordination numbers that range from quasione [7] to twelve [8] and (ii) its $6 s$ electron pair, which may or may not play a role in the stereochemistry of lead(II) complexes [9]. The lone-pair activity can depend on (1) hard or soft ligands, (2) attractive or repulsive interactions among ligands, and (3) the number of electrons (charge) transferred from the ligands to the metal atom [3]. It has been proposed that holodirected structures do not necessarily exclude an inactive lone-pair [10].
The design and synthesis of new materials with desired chemical and physical properties have been of interest, and this involves the generation and study of structural motifs in crystals, which is essentially guided by precise topological control through the manipulation of weak intermolecular interactions [11]. There is a rich variety of intermolecular interactions that serve as tools in engineering such molecular assemblies [12]. Recently, in an effort to explore the role of weak intermolecular interactions among ligands in the stereochemical activity of valence shell electron lone pairs, the lead(II) complexes with fluorinated $\beta$-diketonate and neutral aromatic diamine-chelating ligands have been synthesized and characterized by X-ray crystal structure determination [13-25]. Fluorinated $\beta$-diketonate ligands are very good probes because of their ability for forming intermolecular $\mathrm{C}-\mathrm{H} \cdots \mathrm{F}, \mathrm{F} \cdots \mathrm{F}$, and $\pi \cdots \pi$ interactions. In this paper we report the synthesis and crystal structures of $\left[\mathrm{Pb}(\mathrm{bp})_{2}(\mathrm{btfa})_{2}\right]$ $\mathbf{1}$, where bp and $\mathrm{btfa}^{-}$are the abbreviations of bathophenanthroline and benzoyltrifluoroacetonate ligands, respectively. 


\section{Experimental}

2.1. Material and Measurements. All chemicals were reagent grade and used without further purification. FT-IR spectra were collected on a Mattson 1000 spectrophotometer using $\mathrm{KBr}$ pellets in the range of $4000-450 \mathrm{~cm}^{-1}$. Elemental analyses $(\mathrm{CHN})$ were performed using a Carlo ERBA model EA 1108 analyzer and ${ }^{1} \mathrm{H}$ NMR spectra were obtained with a Bruker spectrometer at $250 \mathrm{MHz}$ in [D6]DMSO. Thermal analyses were carried out on a Perkin-Elmer instrument (Seiko Instruments).

2.2. Crystallography. For the crystal structure determination, the single crystal of compound 1 was used for data collection on a four-circle Rigaku R-AXIS RAPID-S diffractometer equipped with a two-dimensional area IP detector. The graphitemonochromatized Mo-Ka radiation $(\lambda=0.71073 \AA$ ) and oscillation scans technique with $\Delta \omega=5^{\circ}$ for one image were used for data collection. The lattice parameters were determined by the least-squares methods on the basis of all reflections with $F^{2}>2 \sigma\left(F^{2}\right)$. Integration of the intensities, correction for Lorentz, polarization effects, and cell refinement was performed using CrystalClear (Rigaku/MSC Inc., 2005) software [26]. The structures were solved by direct methods using SHELXS-97 [27] and refined by a full-matrix least-squares procedure using the SHELXL-97 program [27]. The final difference Fourier maps showed no peaks of chemical significance. Details of crystal data, data collection, structure solutions, and refinements are given in Table 1.

2.3. Preparation of $\left[\mathrm{Pb}(\mathrm{bp})_{2}(\mathrm{btfa})_{2}\right](1)$. Bathophenanthroline $(0.184 \mathrm{~g}, 1 \mathrm{mmol})$ was placed in one arm of a branched tube [28] and lead(II) acetate $(0.190 \mathrm{~g}, 0.5 \mathrm{mmol})$, and "Hbtfa" (0.206 g, $1 \mathrm{mmol})$ in the other. Methanol and ethanol ratio $(2: 3)$ was carefully added to fill arms, the tube sealed, and the ligand containing arm immersed in a bath at $60^{\circ} \mathrm{C}$ while the other was at ambient temperature. After 3 days, crystals had been deposited in the cooler arm which were filtered off, washed with acetone and ether, and dried in air, yield: $56 \%$. M.p. $250^{\circ} \mathrm{C}$ Analysis: found: C: $62.54, \mathrm{H}$ : 3.20, N: 4.51\%. Calculated for $\mathrm{C}_{68} \mathrm{H}_{44} \mathrm{~F}_{6} \mathrm{~N}_{4} \mathrm{O}_{6} \mathrm{~Pb}: \mathrm{C}: 62.66$, $\mathrm{H}: 3.38, \mathrm{~N}, 4.30 \%$. IR ( $\left.\mathrm{cm}^{-1}\right)$ selected bands: 680 (versus), 845 (versus) (C-H), 956 (m), 1032 (s), 1156 (s), 1224 (versus, C-F), 1400, 1480, 1585 (s, aromatic ring), 1629 (versus, $\mathrm{C}=\mathrm{O}$ ), 3062 (w, C-H aromatic). ${ }^{1} \mathrm{H}$ NMR (DMSO, $\delta): 9.00-9.20(\mathrm{~m}, 4 \mathrm{H}), 7.00-8.00(\mathrm{~m}, 18 \mathrm{H}), 5.86(\mathrm{~s}, 2 \mathrm{H}$, $=\mathrm{CH}-$ ) ppm. ${ }^{13} \mathrm{C}$ NMR (DMSO, $\left.\delta\right): 97.33$ (=CH-), 117.60 $\left(-\mathrm{CF}_{3}\right), 124.52-138.11$ (aromatic carbons), 137.57-153.10 ((hetero)aromatic C-atoms), $168.50(\mathrm{C}=\mathrm{O}), 179.90(\mathrm{C}=\mathrm{O})$ ppm.

\section{Result and Discussion}

3.1. Preparation and Thermal Behavior. The reaction conditions always have great effect on the single-crystal growth. Interestingly, the molar ratio of solvents is important for the growth of single crystals.
TABLE 1: Crystal data and structure refinement for (1).

\begin{tabular}{lc}
\hline Identification code & {$\left[\mathrm{Pb}(\mathrm{dpphen})_{2}(\mathrm{tfpb})_{2}\right]$} \\
Empirical formula & $\mathrm{C}_{68} \mathrm{H}_{46} \mathrm{~F}_{6} \mathrm{~N}_{4} \mathrm{O}_{4} \mathrm{~Pb}$ \\
Formula weight & 1304.3 \\
Crystal system & monoclinic \\
Space group & $\mathrm{C} 2 / \mathrm{c}$ \\
Unit cell dimensions & $a=12.0945(2) \AA$ \\
& $b=31.6546(9) \AA$ \\
& $c=15.2474(4) \AA$ \\
& $\beta=94.955(3)^{\circ}$ \\
Volume & $5815.6(2) \AA$ \\
$Z$ & 4 \\
Density (calculated) & $1.487 \mathrm{~g} \mathrm{~cm}{ }^{-3}$ \\
Absorption coefficient & $2.973 \mathrm{~mm}{ }^{-1}$ \\
$F(000)$ & 2600 \\
$\Theta$-range for data collection & 2.16 to 26.47 \\
Index ranges & $-15 \leq \mathrm{h} \leq 15$ \\
& $-39 \leq \mathrm{k} \leq 39$ \\
Reflections collected & $-19 \leq 1 \leq 19$ \\
Independent reflections & 57689 \\
Completeness to theta & $5963[R(\mathrm{int})=0.14]$ \\
Data/restraints/parameters & $99.1 \%$ \\
Goodness of fit on $F^{2}$ & $3795 / 0 / 383$ \\
Final $R$. $\left[I_{0}>2 \sigma\left(I_{0}\right)\right]$ & 1.043 \\
Largest diff. peak, hole & $0.092, \mathrm{wR} 2=0.1996$ \\
\hline & $0.144, \mathrm{wR} 2=0.228$ \\
& $1.576,-0.808 \mathrm{e} . \AA$ \\
\hline
\end{tabular}

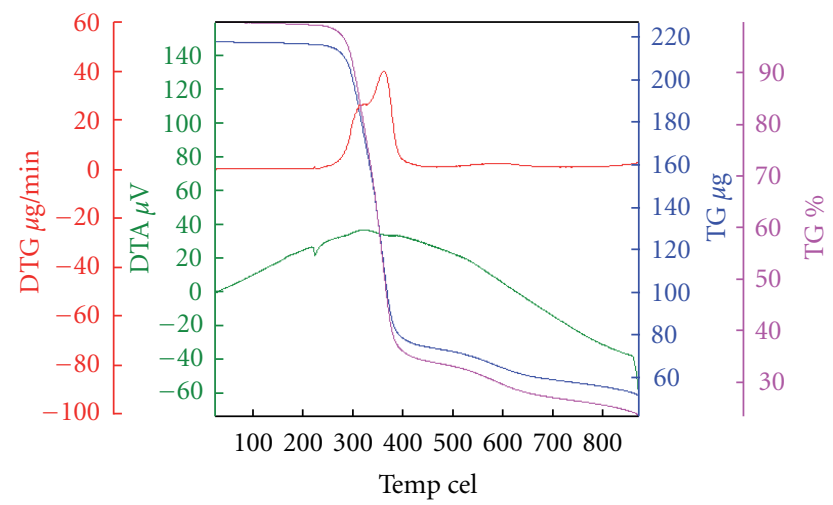

Figure 1: Thermal behavior of $\left[\mathrm{Pb}(\mathrm{bp})_{2}(\mathrm{btfa})_{2}\right](\mathbf{1})$.

In order to examine the thermal stability of the compound, thermal gravimetric (TG) and differential thermal analyses (DTA) were carried out for complex 1 between 30 and $800^{\circ} \mathrm{C}$ in the static atmosphere of air (Figure 1). The TG curve of compound $\mathbf{1}$ indicates that this compound decomposes at $300^{\circ} \mathrm{C}$ ( 1 has good thermal stability related to reported structures of $\mathrm{Pb}(\mathrm{II})$ with $\beta$-diketonates [13-25]). The ligands bp and $\mathrm{btfa}^{-}$decompose at $300-800^{\circ} \mathrm{C}$ with exothermic effect. The solid residue formed is suggested to be $\mathrm{PbO}$ (observed 19.50\%, calcd. 17.12\%). 


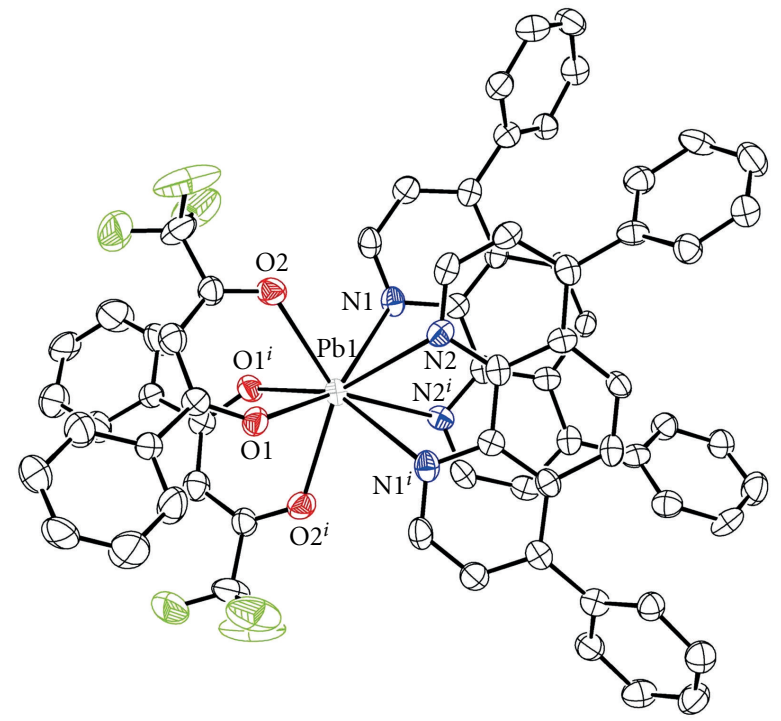

(a)

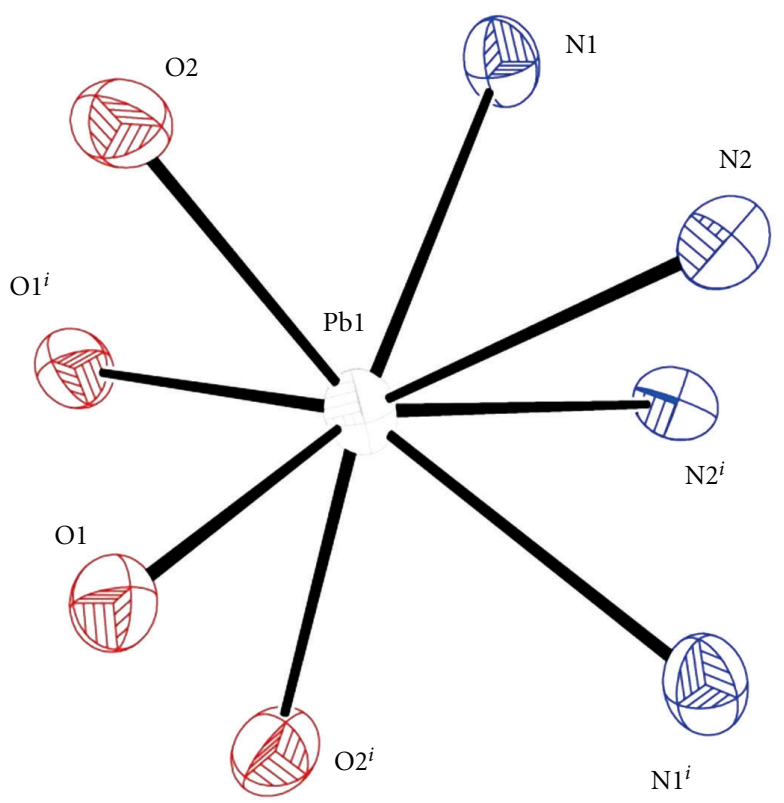

(b)

FIgURE 2: (a) Ortep diagram of complex 1. (b) Representation of the hole in the coordination sphere of $\mathbf{1}$. The coordination geometry is as holodirected [symmetry code $(i):-x, y, 1 / 2-z$ ].

3.2. Structural Description. The solid-state structure of compound 1 was determined by single-crystal X-ray diffraction. The $\mathrm{Pb}(\mathrm{II})$ complex crystallizes in the monoclinic space group $\mathrm{C} 2 / \mathrm{c}$ (Table 1 ). The asymmetric unit contains half of the molecule and it has the $C_{2}$ symmetry (Figure 2). Selected bond lengths, and angles are listed in Table 2. The molecule contains one $\mathrm{Pb}(\mathrm{II})$, two "Bathophenanthroline" ligands and two benzoyltrifluoroacetonates anions (Figure $2(\mathrm{a}))$. The coordination number of $\mathrm{Pb}$ (II) in this complex is eight and each lead atom is chelated by four nitrogens of "bp" ligands with $\mathrm{Pb}-\mathrm{N}$ distances of 2.779 (3), 2.871 (3) $\AA$, and four

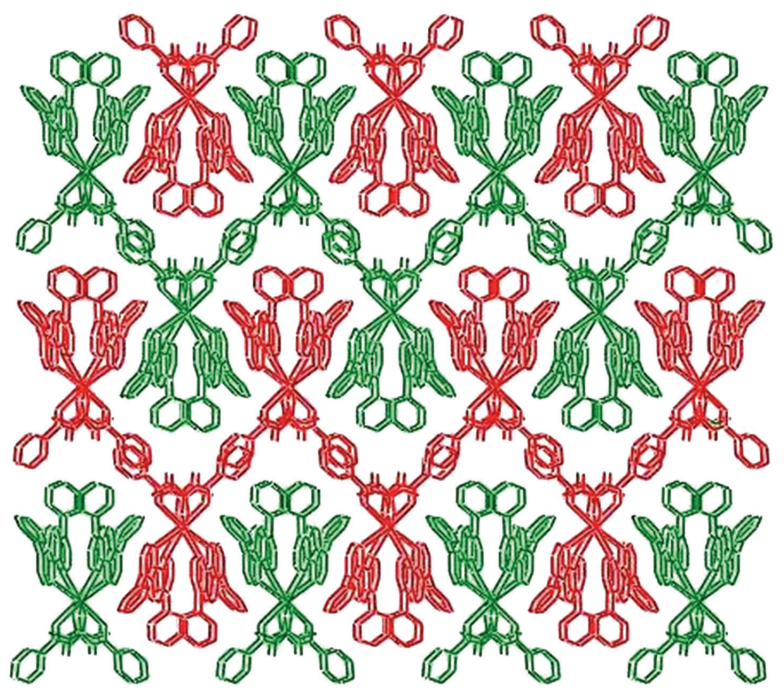

FIgURE 3: Perspective view of the complex down the $a$-axis, packing of mononuclear complex 1 forms $3 \mathrm{D}$ networks via $\pi-\pi$ interactions.

TABLE 2: Selected bond lengths ( $\AA$ ) and angles $\left({ }^{\circ}\right)$ for (1).

\begin{tabular}{lccc}
\hline $\mathrm{Pb}-\mathrm{N} 1$ & $2.779(9)$ & $\mathrm{Pb}-\mathrm{O} 1$ & $2.482(8)$ \\
$\mathrm{Pb}-\mathrm{N} 1^{i}$ & $2.779(9)$ & $\mathrm{Pb}-\mathrm{O} 1^{i}$ & $2.482(8)$ \\
$\mathrm{Pb}-\mathrm{N} 2$ & $2.871(10)$ & $\mathrm{Pb}-\mathrm{O} 2$ & $2.506(8)$ \\
$\mathrm{Pb}-\mathrm{N} 2^{i}$ & $2.871(10)$ & $\mathrm{Pb}-\mathrm{O} 2^{i}$ & $2.506(8)$ \\
$\mathrm{O}^{i}-\mathrm{Pb} 1-\mathrm{O} 1^{i}$ & $91.8(4)$ & $\mathrm{O}^{i}-\mathrm{Pb} 1-\mathrm{N} 1$ & $130.2(3)$ \\
$\mathrm{O} 1-\mathrm{Pb} 1-\mathrm{O} 2$ & $71.1(3)$ & $\mathrm{N} 1-\mathrm{Pb} 1-\mathrm{N} 1^{i}$ & $113.3(4)$ \\
$\mathrm{O}^{i}-\mathrm{Pb} 1-\mathrm{O} 2$ & $75.8(3)$ & $\mathrm{O} 1-\mathrm{Pb} 1-\mathrm{N} 2^{i}$ & $153.5(3)$ \\
$\mathrm{O}^{i}-\mathrm{Pb} 1-\mathrm{N} 1$ & $84.4(3)$ & $\mathrm{O}^{i}-\mathrm{Pb} 1-\mathrm{N} 2^{i}$ & $99.2(3)$ \\
$\mathrm{O} 2-\mathrm{Pb} 1-\mathrm{N} 2^{i}$ & $135.0(3)$ & $\mathrm{N} 1-\mathrm{Pb} 1-\mathrm{N} 2^{i}$ & $56.3(3)$ \\
$\mathrm{O} 2-\mathrm{Pb} 1-\mathrm{O} 2^{i}$ & $131.7(4)$ & $\mathrm{N} 1^{i}-\mathrm{Pb} 1-\mathrm{N} 2^{i}$ & $73.9(3)$ \\
$\mathrm{O} 1-\mathrm{Pb} 1-\mathrm{N} 1$ & $149.6(3)$ & $\mathrm{O} 2-\mathrm{Pb} 1-\mathrm{N} 2$ & $85.0(3)$ \\
$\mathrm{O} 2-\mathrm{Pb} 1-\mathrm{N} 1$ & $78.7(3)$ & $\mathrm{N} 2^{i}-\mathrm{Pb} 1-\mathrm{N} 2$ & $81.5(4)$ \\
\hline
\end{tabular}

$i:-x, y, 1 / 2-z$.

oxygens of two "btfa" " anions with $\mathrm{Pb}-\mathrm{O}$ distances of 2.482 (4) and 2.506 (4) Å (Figure 2(b)).

The arrangement of bathophenanthrolines and benzoyltrifluoroacetonates does not suggest any gap or hole in coordination geometry around the metal ion (Figure 1(b)), indicating that the lone pair of electrons on lead(II) is inactive and the geometry around $\mathrm{Pb}$ (II) sphere is holodirected [29]. According to suggestions of Shimoni-Livny et al. [3, 4] the hemidirected geometry is present in all lead(II) compounds with low coordination numbers (2-5) and also quite common for coordination numbers of 6 to 8 , while holodirected geometry becomes dominant at high coordination numbers of 9 and 10. Since the presence of four bulk ligands increases steric crowding around lead(II) and results in strong interligand repulsions. This may be the reason of the disappearance of the gap in the coordination polyhedron, thereby resulting in less common holodirected geometry. 
TABLE 3: Inter- and intramolecular interactions for $\mathbf{1}$

\begin{tabular}{lcc}
\hline $\mathrm{A} \cdots \mathrm{H}-\mathrm{B}$ & $\mathrm{A} \cdots \mathrm{H} / \AA$ & $\mathrm{A} \cdots \mathrm{B} / \AA$ \\
$\mathbf{1}$ & 2.725 & $3.360(2)$ \\
$\mathrm{O} 1 \cdots \mathrm{H} 28-\mathrm{C} 28(-x,-y, 1-z)$ & 2.707 & $3.308(2)$ \\
$\mathrm{F} 3 \cdots \mathrm{H} 19-\mathrm{C} 19(x,-y,-1 / 2+z)$ & - & 2.868 \\
$\mathrm{~F} 2 \cdots \mathrm{F} 2(1-x, y, 1 / 2-z)$ & - & 3.496 \\
$\pi \cdots \pi$ (inter, slipped face-to-face between bp ligands) & - & 3.507 \\
$\pi \cdots \pi$ (slipped edge-to-adge between aromatic rings of btfa ${ }^{\circ}$ ) & - & 3.586 \\
$\pi \cdots \pi$ (intra, slipped face-to-face between bp ligands) & - & - \\
\hline
\end{tabular}

A search was generally made for intermolecular approaches in the complex $\left[\mathrm{Pb}(\mathrm{bp})_{2}(\mathrm{btfa})_{2}\right](1)$. The interesting feature is that there are F...F interactions, the weak hydrogen bonding, between the flourine atoms of btfa ${ }^{-}$with the distances of $\mathrm{F} 2 \cdots \mathrm{F} 2(1-x, y, 1 / 2-z)=2.868 \AA$ and $\mathrm{F} \cdots \mathrm{H}-\mathrm{C}, \mathrm{O} \cdots \mathrm{H}-\mathrm{C}$ interactions (Table 3 ) values suggest strong interactions within this class of weak noncovalent contacts [30]. There are $\pi-\pi$ stacking interactions between the aromatic rings that belong to adjacent chains in $\mathbf{1}$. The interplanar distances range between aromatic rings in this compound is the normal $\pi-\pi$ stacking interaction (Table 3 )

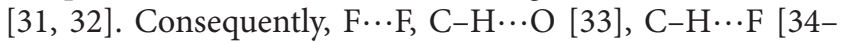
37 ], and $\pi-\pi$ interactions allow the mononuclear complexes to form a hybrid three-dimensional network (Figure 3).

In spite of the recent structural study of fluorine $\beta$-diketonates complexes of $\mathrm{Pb}(\mathrm{II})$ with heteroaromatic ligands (1,10-phenanthroline,2,9-dimethyl-1,10-phenanthroline) and other $\mathrm{Pb}(\mathrm{II})$ compounds using $\mathrm{N}$-donor ligands and diketonates [13-25], this complex is as discrete mononuclear complex, and coordination geometry of $\mathbf{1}$ is holodirected. In recent structural study of dinuclear complexes, fluorine $\beta$-diketonates anion has a role of bridging ligand [13-25].

The obvious question then is whether the weak interactions have stretched coordinate bonds to result in ligand stacking or whether it is the stacking interaction which has imposed a positioning of the donor atoms for forming the weak interactions in the packing. In conclusion, a subtle interplay among lone-pair activity and strong and weak interactions appears to control the packing motifs in the crystal structure of $\mathbf{1}$. Our current results suggest that while interactions involving "organic fluorine" have a significant influence in generating supramolecular assemblies in inorganic solids, the general use of these interactions for the a priori prediction of packing motifs is yet to be fully understood and harnessed.

\section{Disclosure}

Crystallographic data for the structure reported in the paper have been deposited in the Cambridge Crystallographic Data Centre as supplementary publication no. CCDC-864329 for the complex 1. Copies of this information can be obtained for free from The Director, CCDC, 12 Union Road,
Cambridge, CB2 IEZ, UK (fax: p44-1223-336033; e-mail: deposit@ccdc.cam.ac.uk or http://www.ccdc.cam.ac.uk/).

\section{Acknowledgment}

Support of this investigation by Payame Noor University is gratefully acknowledged by F. Marandi.

\section{References}

[1] R. G. Pearson, "Absolute electronegativity and hardness: application to inorganic chemistry," Inorganic Chemistry, vol. 27, pp. 734-740, 1998.

[2] M. Kaupp and P. V. R. Schleyer, "Ab Initio study of structures and stabilities of substituted lead compounds. Why is inorganic lead chemistry dominated by PbII but organolead chemistry by PbIV?" Journal of the American Chemical Society, vol. 115, no. 3, pp. 1061-1073, 1993.

[3] L. Shimoni-Livny, J. P. Glusker, and C. W. Brock, "Lone pair functionality in divalent lead compounds," Inorganic Chemistry, vol. 37, pp. 1853-1867, 1998.

[4] L. Puskar, P. E. Barran, B. J. Duncombe, D. Chapman, and A. J. Stace, "Gas phase study of the chemistry and coordination of $\mathrm{Pb}$ (II) in the presence of oxygen-, nitrogen-, sulphur-, and phosphorous-donating ligands," Journal of Physical Chemistry $A$, vol. 109, no. 1, pp. 273-282, 2005.

[5] J. Emsley, The Elements, Oxford University Press, New York, NY, USA, 1988.

[6] J. E. Huheey, E. A. Keiter, and R. L. Keiter, Inorganic Chemistry, Harper Collins College Publishers, New York, NY, USA, 4th edition, 1993.

[7] S. Hino, M. Brynda, A. D. Phillips, and P. P. Power, "Synthesis and characterization of a quasi-one-coordinate lead cation," Angewandte Chemie, vol. 43, no. 20, pp. 2655-2658, 2004.

[8] C. E. Holloway and M. Melnik, "Lead coordination and organometallic compounds: classification and analysis of crystallographic and structural data," Main Group Metal Chemistry, vol. 20, no. 7, pp. 399-495, 1997.

[9] R. D. Hancock, A. F. Williams, C. Floriani, and A. E. Merbach, Eds., Perspectives in Coordination Chemistry, VCHA, VCH, Basle, Switzerland, 1992.

[10] C. Janiak, S. Temizdemir, T. G. Scharmann, A. Schmalstieg, and J. Demtschuk, "Hydrotris(1,2,4-triazolyl)borato complexes with the main group elements $\mathrm{Ca}, \mathrm{Sr}$, and $\mathrm{Pb}$-Unexpectedly bent ML2 structures and a stereochemically inactive lone pair at lead(II)," Zeitschrift fur Anorganische und Allgemeine Chemie, vol. 626, no. 10, pp. 2053-2062, 2000. 
[11] K. Müller-Dethlefs and P. Hobza, "Noncovalent interactions: a challenge for experiment and theory," Chemical Reviews, vol. 100, no. 1, pp. 143-167, 2000.

[12] J. M. Lehn, "Supramolecular chemistry," Science, vol. 260, no. 5115, pp. 1762-1763, 1993.

[13] F. Marandi, Z. Nikpey, M. Khosravi, H.-K. Fun, and M. Hemamalini, "Synthesis and characterization of lead(II) complexes with substituted 2,2-bipyridines, trifluoroacetate, and furoyltrifluoroacetonate," Journal of Coordination Chemistry, vol. 64, pp. 3012-3021, 2011.

[14] F. Marandi and A. Morsali, "Sonochemical syntheses and characterization of a new nano-structured one-dimensional lead(II) coordination polymer with 4,4,4-trifluoro-1-phenyl1,3-butandione," Inorganica Chimica Acta, vol. 370, no. 1, pp. 526-530, 2011.

[15] F. Marandi, R. Rutvand, M. Rafiee, J. H. Goh, and H.-K. Fun, "Synthesis, properties and crystal structures of new binuclear lead(II) complexes based on phenyl, naphthyl-containing fluorine beta-diketones and substituted 2,2 $2^{\prime}$-bipyridines," Inorganica Chimica Acta, vol. 363, no. 14, pp. 4000-4007, 2010.

[16] F. Marandi, Z. Nikpey, J. H. Goh, and H.-K. Fun, "Synthesis and crystal structure of lead(II) thenoyltrifluoroacetonate complexes with substituted $2,2^{\prime}$-bipyridines: interplay of intermolecular interactions in crystals," Zeitschrift Fur Naturforschung, vol. 65, pp. 128-134, 2010.

[17] F. Marandi and H. Krautscheid, "Synthesis and characterization of lead(II) complexes with the 4-methoxybenzoyltrifluoroacetonate ligand," Zeitschrift fur Naturforschung, vol. 64, no. 9, pp. 1027-1031, 2009.

[18] F. Marandi, S. Chantrapromma, and H.-K. Fun, "Synthesis and spectroscopic studies of mixed-ligand complexes of lead(II) hexafluoroacetylacetonate including the crystal structure of $\left.\left[\mathrm{Pb}_{2} \text { (phen }\right)_{4}(\mathrm{hfa})_{2}\left(-\mathrm{NO}_{3}\right)_{2}\right]$," Journal of Coordination Chemistry, vol. 62, no. 2, pp. 249-256, 2009.

[19] H. Ahmadzadi, F. Marandi, and A. Morsali, "Structural and $\mathrm{X}$-ray powder diffraction studies of nano-structured lead(II) coordination polymer with eta(2) $\mathrm{Pb}$ center dot center dot center dot C interactions," Journal of Organometallic Chemistry, vol. 694, pp. 3565-3569, 2009.

[20] F. Marandi, M. Khosravi, and H.-K. Fun, "Spectroscopic, thermal and structural studies of Aza-aromatic base adducts of cadmium furoyltrifluoroacetonate," Zeitschrift fur Anorganische und Allgemeine Chemie, vol. 634, pp. 2617-2622, 2008.

[21] F. Marandi and H.-K. Fun, "Supramolecular structure formed by directed intermolecular interactions in a lead(II) complex," Zeitschrift fur Anorganische und Allgemeine Chemie, vol. 634, no. 6-7, pp. 1123-1126, 2008.

[22] F. Marandi, A. Aslani, and A. Morsali, "Fluorine-substituted beta-diketonate $\mathrm{Pb}$-II complexes, $\left[\mathrm{Pb}(\right.$ phen $\left.)(\mathrm{TFPB})_{2}\right]$ and $\left[\mathrm{Pb}\left(2,2^{\prime}\right.\right.$-bipy $\left.)(\mathrm{TFPB})_{2}\right]$," Journal of Coordination Chemistry, vol. 61, no. 6, pp. 882-890, 2008.

[23] F. Marandi, A. Morsali, and A. A. Soudi, "Labile interactions in aza-aromatic base adducts of lead(II) thenoyltrifluoroacetonate," Zeitschrift fur Anorganische und Allgemeine Chemie, vol. 633, no. 4, pp. 661-665, 2007.

[24] F. Marandi, N. Asghari, M. Gorbanloo, A. A. Soudi, and P. Mayer, "Synthesis and crystal structure of $[\mathrm{Pb}(\operatorname{trz})(\mathrm{tfpb})$ $\left(\mathrm{H}_{2} \mathrm{O}\right)$ ]: a lead(II) complex containing 2,4,6-tris(2-pyridyl)1,3,5-triazine and 4,4,4- trifluoro-1-phenyl-1,3-butandionate," Zeitschrift fur Anorganische und Allgemeine Chemie, vol. 633, no. 4, pp. 536-538, 2007.
[25] J. M. Harrowfield, F. Marandi, and A. A. Soudi, "Fluorous interactions in complexes of lead(II)hexafluoroacetylacetonate," Inorganica Chimica Acta, vol. 358, pp. 4099-4103, 2005.

[26] Rigaku, CrystalClear, Version 1.3.6, Rigaku American Corporation, The Woodlands, Tex, USA, 2005.

[27] G. M. Sheldrick, SHELXS97 and SHELXL97, University of Gottingen, Berlin, Germany, 1997.

[28] F. Marandi, F. Amoopour, I. Pantenburg, and G. Meyer, "Synthesis and crystal structure of two new lead(II) coordination polymers with substituted 2,2I-bipyridine ligands with dicyanamide and nitrate as co-ligands," Journal of Molecular Structure, vol. 973, no. 1- 3, pp. 124-129, 2010.

[29] A. Ramazani, S. Hamidi, and A. Morsali, "A novel mixedligands holodirected two-dimensional lead(II) coordination polymer as precursor for preparation lead(II) oxide nanoparticles," Journal of Molecular Liquids, vol. 157, no. 1, pp. 73-77, 2010.

[30] A. R. Choudhury, U. K. Urs, T. N. Guru Row, and K. Nagarajan, "Weak interactions involving organic fluorine: a comparative study of the crystal packing in substituted isoquinolines," Journal of Molecular Structure, vol. 605, no. 1, pp. 71-77, 2002.

[31] C. Janiak, "A critical account on $\Pi-\Pi$ stacking in metal complexes with aromatic nitrogen-containing ligands," Journal of the Chemical Society, Dalton Transactions, pp. 3885-3896, 2000.

[32] Z.-H. Liu, C.-Y. Duan, J.-H. Li, Y.-J. Liu, Y.-H. Mei, and X.-Z. You, "Structural dependence of $\Pi-\Pi$ interactions in dithiocarbazato and thiosemicarbazato nickel complexes," New Journal of Chemistry, vol. 24, pp. 1057-1062, 2000.

[33] G. R. Desiraju and T. Steiner, "The weak hydrogen bond," in IUCr Monograph on Crystallography, vol. 9, Oxford Science, Oxford, UK, 1999.

[34] E. D'Oria and J. J. Novoa, "On the hydrogen bond nature of the $\mathrm{C}-\mathrm{H} \cdots \mathrm{F}$ interactions in molecular crystals. An exhaustive investigation combining a crystallographic database search and ab initio theoretical calculations," CrystEngComm, vol. 10, pp. 423-436, 2008.

[35] S. Takahashi, T. Jukurogi, T. Katagiri, and K. Uneyama, "Isomorphic supramolecular structures via one-dimensional hydrogen bonding motifs in crystals of chiral difluorolactates, trichlorolactates and trifluorolactates," CrystEngComm, vol. 8, no. 4, pp. 320-326, 2006.

[36] A. R. Choudhury and T. N. G. Row, "Organic fluorine as crystal engineering tool: evidences from packing features in fluorine substituted isoquinolines," CrystEngComm, vol. 8, no. 265, pp. 274-2006.

[37] J. Ruiz, V. Rodríguez, C. Haro, A. Espinosa, J. Pérez, and C. Janiak, "New 7-azaindole palladium and platinum complexes: crystal structures and theoretical calculations. In vitro anticancer activity of the platinum compounds," Dalton Transactions, vol. 39, pp. 3290-3301, 2010. 

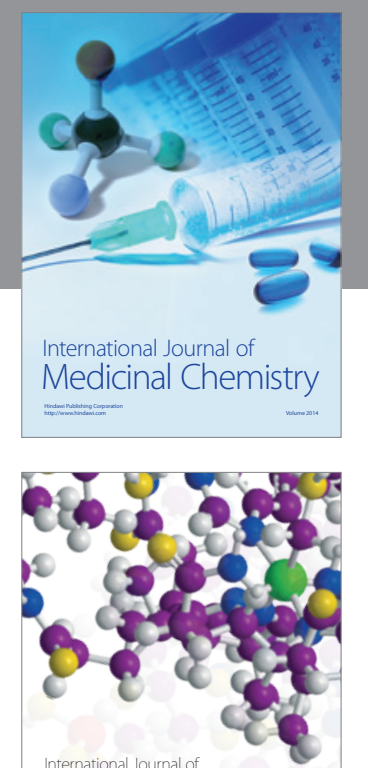

\section{Carbohydrate} Chemistry

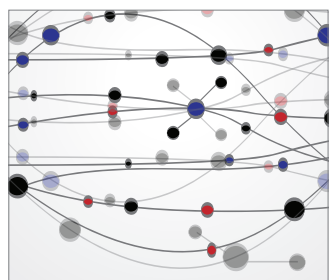

The Scientific World Journal
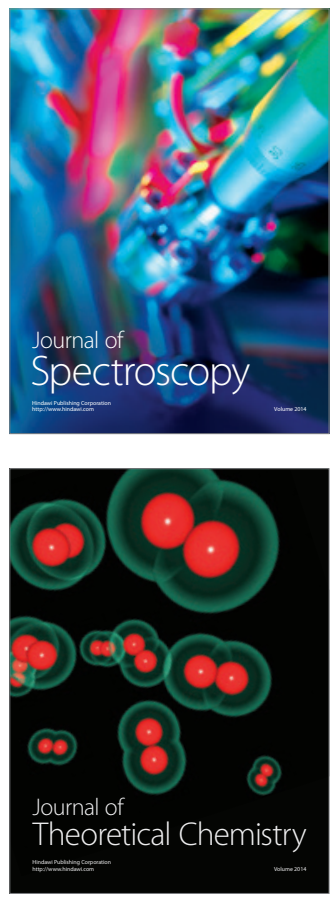
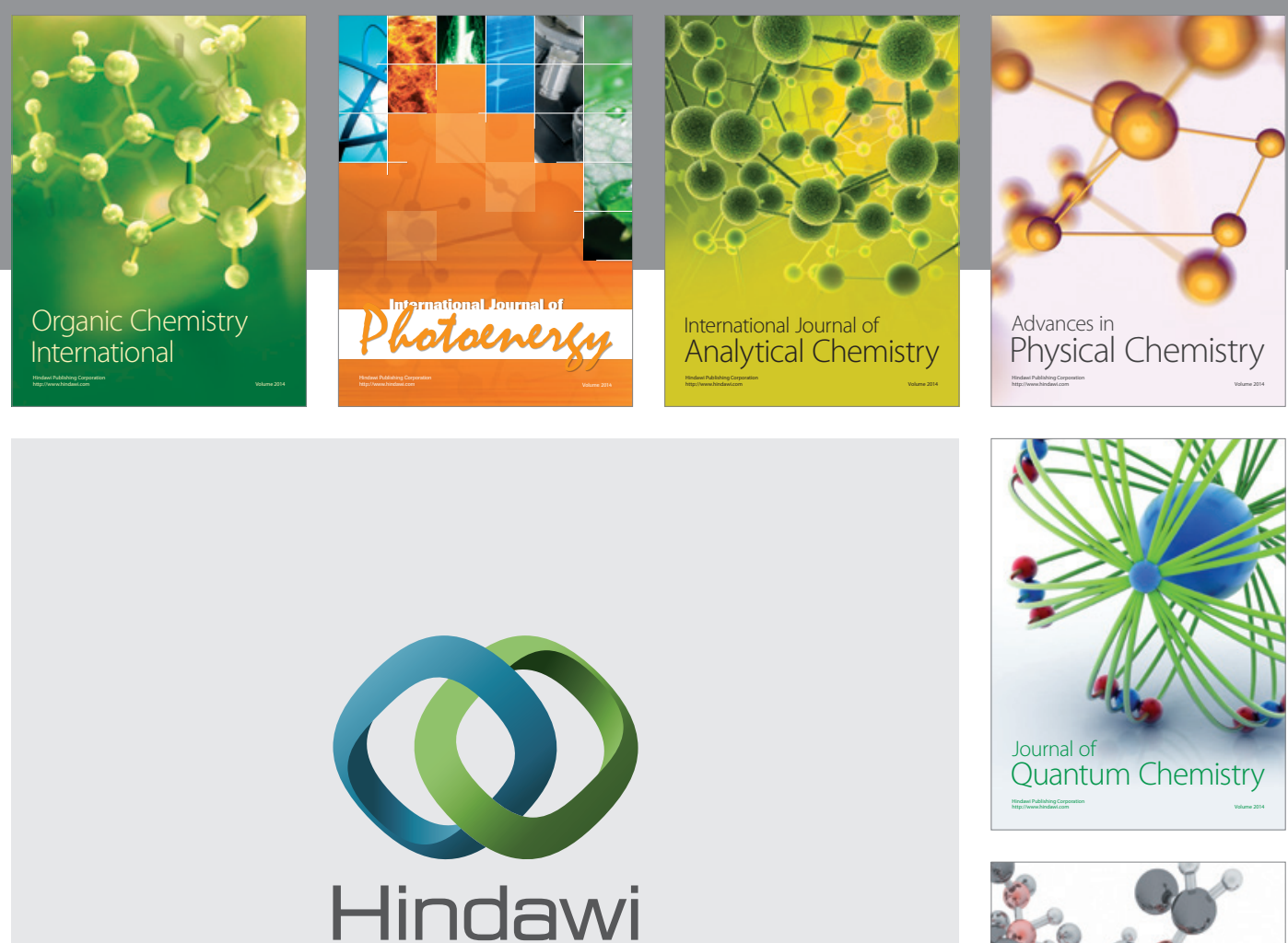

Submit your manuscripts at

http://www.hindawi.com

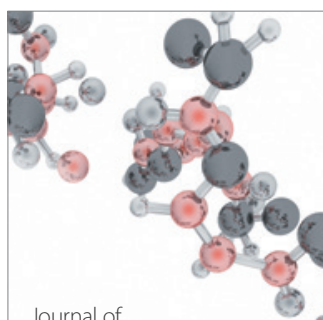

Analytical Methods

in Chemistry

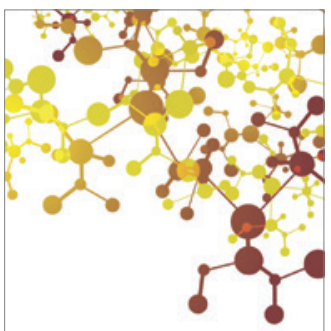

Journal of

Applied Chemistry

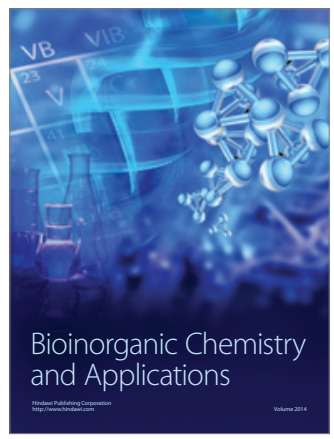

Inorganic Chemistry
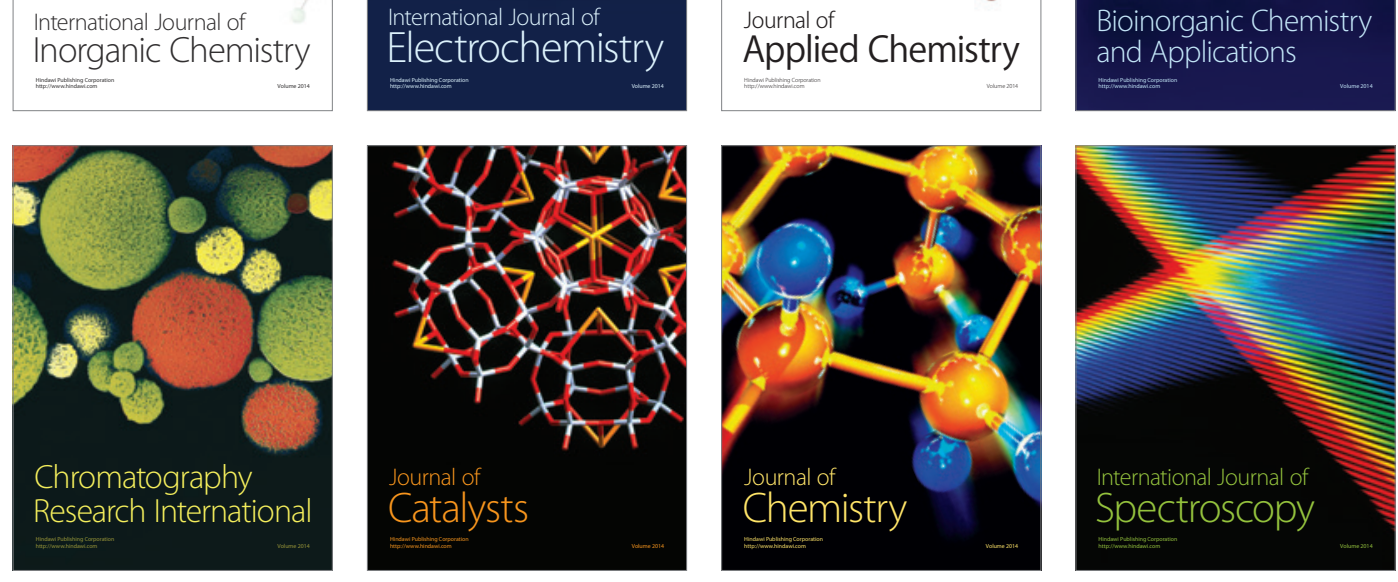